\title{
MANEJO CULTURAL DO MARACUJAZEIRO-AMARELO EM CICLO ANUAL VISANDO À CONVIVÊNCIA COM O VÍRUS DO ENDURECIMENTO DOS FRUTOS: UM ESTUDO DE CASO ${ }^{1}$
}

\author{
ALOÍSIO COSTA SAMPAIO², NILTON SCUDELLER ${ }^{3}$, TEREZINHA DE FÁTIMA FUMIS ${ }^{2}$, \\ APARECIDA MARQUES DE ALMEIDA ${ }^{4}$, RAQUEL NAKASATO PINOTTI ${ }^{4}$, \\ MARIA JOSÉ DE MARCHI GARCIA ${ }^{4}$, MARIA LÚCIA PALLAMIN ${ }^{5}$
}

RESUMO - Este estudo de caso teve por objetivo analisar a qualidade dos frutos e a produtividade em t/ha de maracujá-amarelo, em dois ciclos anuais, plantados, respectivamente, nos dias 04-10-04 ( $1^{\circ}$ plantio) e 20-08-05 (2ºntio). As mudas da seleção Afruvec foram formadas em tubetes no interior de estufa com tela antiafídeo. O pomar, nos dois ciclos produtivos, foi irrigado por gotejamento, adotando-se uma densidade de 1.600 plantas/ha. O $1^{\circ}$ plantio foi erradicado no dia 13-07-05, em função de o pomar apresentar a totalidade das plantas com sintomas típicos do vírus do endurecimento dos frutos (PWV) nas folhas e frutos. No $1^{\circ}$ e no $2^{\circ}$ plantios, os sintomas tiveram início no dia 26-01-05 e no dia 04-01-06, respectivamente. Não houve necessidade de eliminação de plantas em ambos os plantios, já que o início dos sintomas de PWV ocorreu quando as plantas se encontravam em pleno florescimento. Pelos resultados, pode-se concluir que o manejo adotado regionalmente, com plantio em ciclo anual, permitiu uma ampliação do período de colheita, decorrente da antecipação de plantio no $2^{\circ}$ ano; uma produtividade de $16,94 \mathrm{~kg} / \mathrm{planta}$ e $18,39 \mathrm{~kg} / \mathrm{planta}$, no $1^{\circ}$ e $2^{\circ}$ anos, respectivamente; um aumento da rentabilidade na safra de 2006 em função: da maior produção, melhor cotação dos frutos para mesa e indústria, e aproveitamento dos investimentos realizados no $1^{\circ}$ ano. As técnicas empregadas promoveram uma eficiente redução do potencial de inóculo regional, favorecendo uma sustentabilidade na produção.

Termos para indexação: Passiflora edulis Sims f. flavicarpa Deg., sustentabilidade, virose.

\section{HANDLING OF THE OF YELLOW PASSION FRUIT PLANT IN ANNUAL CYCLE AIMING THE COEXISTENCE WITH THE PWV (PASSION FRUIT WOODINESS VIRUS): A CASE STUDY}

ABSTRACT - This case study aimed to analyze the quality of fruits and productivity in $\mathrm{t} / \mathrm{ha}$ of the yellow passion fruit in two annual cycles, respectively on October $4^{\text {th }}, 2004\left(1^{\text {st }}\right.$ planting $)$ and August $20^{\text {th }}, 2005$ ( $2^{\text {nd }}$ planting $)$. In the $1^{\text {st }}$ planting it was eradicated on the July $13^{\text {th }}, 2005$, in function of the orchard presenting the totality of the plants with typical symptoms of PWV in fruits and leaves. The seedlings of the selection Afruvec were formed in plastic tubes inside greenhouse with anti-aphid screen. The orchard in both productive cycles was irrigated by leaking being adopted a density of 1.600 plants per hectare. In both plantings there was no necessity of elimination of plants, since the beginning of the symptoms of PWV happened when the plants were in the middle of the flowering. In the $1^{\text {st }}$ planting the symptoms began on the January $26^{\text {th }}, 2005$ and in the $2^{\text {nd }}$ planting, on the January $4^{\text {th }}, 2006$. For the results, it can be concluded that the regionally handling adopted with annual cycle planting, allowed an amplification of the crop period, due to the planting anticipation of the $2^{\text {nd }}$ year, productivity of $16,94 \mathrm{~kg} / \mathrm{plant}$ and $18,39 \mathrm{~kg} / \mathrm{plant}$, in the $1^{\text {st }}$ and $2^{\text {nd }}$ year, respectively; increase the profitability in the crop of 2006 in function of the best production and quotation of the fruits "in natura" and for industry; and mainly, a reduction of the potential of regional inoculum, seeking a sustainable production.

Index terms: Passiflora edulis Sims f. flavicarpa Deg., sustainability, viruses.

\section{INTRODUÇÃO}

O Brasil é o maior produtor mundial de maracujá, sendo que a produção nacional cresceu no período de 1990 até 1996, passando de 317.236 para 409.497 toneladas. Após dois anos, a produção reduziu drasticamente, atingindo 298.255 toneladas e, posteriormente, estabilizando-se nos anos de 2003 e 2004, em 485.342 e 491.619 toneladas, respectivamente (IBGE, 2006). Essas variações bruscas de produção são decorrentes principalmente da incidência endêmica do vírus do endurecimento dos frutos a partir de 1996, em importantes regiões produtoras de maracujá.

Segundo Yuki et al. (2006), a cultura do maracujazeiro pode ser infectada por diversas viroses, porém o vírus do endurecimento dos frutos (PWV) é o que predomina e o que causa os maiores prejuízos. Em virtude da alta incidência, a cultura vem tornando-se anual, pois, antes de ocorrerem as epidemias, a cultura era perene e cultivada pelo menos três anos consecutivos.

Nascimento et al. (2004), ao realizarem análise filogenética de Potyvírus causando endurecimento dos frutos do

'(Trabalho 119-07).Recebido em: 07-05-2007. Aceito para publicação em: 18-10-2007. Dados de produção e comercialização de Associado da Bauru Frutas em dois ciclos de colheita.

${ }^{2}$ Prof. Assist-Doutor(a) da UNESP - Campus de Bauru - Depto de Ciências Biológicas, C.P. 473, CEP 17033.360 - E-mail: aloisio@fc.unesp.br.

${ }^{3}$ Fruticultor da BauruFrutas (Associação de Fruticultores de Bauru e região).

${ }^{4}$ Pesq. Científica da APTA - Unidade de Pesquisa e Desenvolvimento de Bauru.

${ }^{5}$ Mestranda em Horticultura da FCA/Unesp/Botucatu.

Rev. Bras. Frutic., Jaboticabal - SP, v. 30, n. 2, p.343-347, Junho 2008 
maracujazeiro, no Nordeste do Brasil, observaram identidade com isolados de Cowpea aphid-borne mosaic vírus (CABMV) de 86 a 94\%, e com isolados de Passionfruit woodiness vírus (PWV) de 68 a 76\%. De acordo com Zerbini et al. (2006), o endurecimento dos frutos do maracujazeiro pode ser causado pelas duas espécies de vírus, sendo uma das principais doenças da cultura. Barbosa et al. (2005) relataram que o CABMV e o PWV são transmitidos por pulgões e mecanicamente, sendo que o primeiro pode ser transmitido por semente.

Com relação à sintomatologia da virose, Rezende (2006) menciona o mosaico comum, acompanhado em alguns casos de enrugamento, deformações e bolhas no limbo foliar. Os sintomas foliares podem diminuir em intensidade ou quase desaparecerem em algumas folhas da haste e retornarem posteriormente nas folhas mais novas, dependendo da estirpe do vírus e das condições ambientais. De acordo com Gioria et al. (2000), a produção é reduzida quantitativa e qualitativamente, já que os frutos ficam menores, deformados e endurecidos, podendo até exibir rachaduras, dependendo da estirpe do vírus.

Estudos epidemiológicos do PWV mostraram que a relação vírus-vetor é do tipo não- persistente, ou seja, tanto a aquisição como a inoculação do vírus pelo inseto são rápidas, em questão de segundos, durante as picadas de prova (Yuki et al., 2006). Segundo os autores, apesar de a disseminação ser realizada por várias espécies de afídeos, as do gênero Aphis foram as mais abundantes na região produtora da Alta Paulista (SP). Novaes (2002), ao estudar o controle do PWV através da seleção de estirpes fracas do vírus, observou que a premunização não parece ser uma alternativa adequada para o controle do endurecimento dos frutos do maracujazeiro, devido à falha de proteção. Essa quebra de proteção parece estar relacionada com a baixa concentração e/ou distribuição irregular das estirpes fracas nas folhas do maracujazeiro, que propiciam a existência de sítios de infecção para a estirpe severa posteriormente inoculada.

Visando a viabilizar economicamente a produção, algumas medidas têm sido recomendadas, tais como: utilização de mudas sadias, obtidas em viveiros telados; erradicação sistemática das plantas com sintomas nas folhas até o florescimento (roguing); eliminação de pomares velhos ou abandonados antes do início da nova plantação; cuidados nas operações de poda e desbrota para evitar a transmissão mecânica do vírus; aumento da densidade de plantio; uso de irrigação localizada e, se possível, plantios em locais isolados (São José, 1998; Gioria et al., 2000; Vianna et al., 2003; Barbosa et al., 2005; Rezende, 2006; Oliveira, 2006). Empregando-se essas técnicas, objetivou-se, com este trabalho, avaliar a produtividade, a qualidade dos frutos e a rentabilidade do maracujá-amarelo em dois ciclos produtivos, na região de Bauru (SP), sob condições irrigadas.

\section{MATERIAL E MÉTODOS}

O trabalho foi realizado na Fazenda São João, Município de Bauru-SP (S 22 $15^{\prime} 48^{\prime \prime}$ e W 4904'85"), em pomar comercial de maracujazeiro-amarelo (Passiflora edulis Sims f. flavicarpa Deg.), seleção Afruvec, irrigado por gotejamento. O clima da região é subtropical seco no inverno.
As mudas foram formadas no interior de estufa fechada com tela antiafídeo, sendo a semeadura realizada em tubetes de polietileno contendo substrato à base de casca de pínus. Os tubetes ficaram alojados em bancadas suspensas e, durante o desenvolvimento das mudas, fez-se uso de pulverizações preventivas com defensivos, visando ao controle preventivo da septoriose (Septoria passiflorae), verrugose (Cladosporium spp.), antracnose (Colletotrichum gloeosporioides) e ácaros. Anteriormente ao plantio das mudas no campo, foram realizados calagem em área total mediante análise do solo, plantio de capim napier como quebra-vento ao redor da área e aplicação de $150 \mathrm{~g}$ de superfosfato simples, $100 \mathrm{~g}$ de cloreto de potássio, $50 \mathrm{~g}$ de micronutrientes quelatizado à base de $\mathrm{Mn}, \mathrm{Zn}$ e $\mathrm{B}$, e $100 \mathrm{~g}$ de calcário dolomítico por metro linear de sulco. O sistema de condução foi o de espaldeira simples, com um fio de arame liso a 1,9 m de altura. O espaçamento utilizado foi de $2,5 \mathrm{~m} \times 2,5 \mathrm{~m}$, correspondendo a 1.600 plantas/ha. O pomar foi constituído por 400 plantas, cujo plantio das mudas foi realizado no dia 04-10-04, sendo, posteriormente, tutoradas e submetidas às práticas culturais tradicionais (desbrotas, poda de formação, adubações, polinização manual, pulverização de defensivos e colheita).

Os frutos foram colhidos pela manhã, três vezes por semana, diretamente na espaldeira, mantendo-se o pedúnculo aderido e com $75 \%$ da coloração amarela, no período de 18-03-05 a 11-07-05. No barracão da BauruFrutas (Associação de Fruticultores de Bauru e região), realizou-se a classificação dos frutos em 5 classes (calibres), denominadas $3 \mathrm{~A}$ (diâmetro maior que $85 \mathrm{~mm}), 2 \mathrm{~A}(75-85 \mathrm{~mm}), 1 \mathrm{~A}(65-75 \mathrm{~mm})$, segunda linha (composto por frutos 1; 2 e 3A, com defeitos leves) e indústria (menor que $55 \mathrm{~mm}$ ou com defeitos graves) (Ceagesp, 2001). As plantas foram avaliadas quanto à incidência do vírus do endurecimento dos frutos nas folhas, através dos sintomas típicos de enrugamento, deformações e bolhas no limbo foliar (Rezende, 2006). A produtividade foi mensurada ao longo da safra, e a receita bruta, através da cotação por caixa de $13 \mathrm{~kg}$ (fruta de mesa) ou kg (indústria), após a tabulação da produção obtida por classe.

O pomar, no final do $1^{\circ}$ ano de produção, encontrava-se com a totalidade das plantas com sintomas típicos do vírus do endurecimento dos frutos nas folhas e frutos, porém em diferentes intensidades de agressividade. Visando a reduzir o potencial de inóculo, erradicou-se totalmente o pomar no dia 13-07-05. Após um intervalo de 38 dias, realizou-se novo plantio da seleção Afruvec, no dia 20-08-05, sob condições de irrigação por gotejamento, ampliando-se a área plantada para 1.292 plantas. As práticas culturais adotadas foram similares às empregadas no $1^{\circ}$ plantio. Os primeiros sintomas de PWV ocorreram a partir de 04-01-06, ou seja, o pomar também se encontrava em pleno florescimento, não havendo necessidade de erradicação de plantas. $\mathrm{O}$ sistema de colheita no $2^{\circ}$ ano foi idêntico ao descrito anteriormente, bem como a metodologia para a avaliação da produtividade, qualidade dos frutos e receita bruta obtida no sistema de produção em ciclo anual. O período de colheita teve início no dia 06-02-06 e prolongou-se até o dia 19-07-06. No final do $2^{\circ}$ ciclo de produção, o pomar encontrava-se com a totalidade das plantas com sintomas de PWV.

A rentabilidade econômica foi calculada pela diferença 
entre o lucro bruto e o custo total de cultivo, resultando em lucro líquido. Os custos foram calculados com base nos gastos do sistema de cultivo de maracujá irrigado adotado.

\section{RESULTADOS E DISCUSSÃO}

Os primeiros sintomas do vírus do endurecimento dos frutos nas folhas foram detectados a partir de 26-01-05, ou seja, quando as plantas já estavam formadas e em pleno florescimento, não se empregando corte de plantas (roguing).

As colheitas no $1^{\circ}$ ano tiveram início no dia $18-03-05$ e prolongaram-se até o dia 11-07-05, totalizando 42 entregas de frutos no barracão da BauruFrutas. A produção total foi de 27,12 t/ha, apresentando maior produção de frutos $2 \mathrm{~A}$ (Tabela 1). Durante o período de colheita, os frutos tipo indústria apresentaram um incremento expressivo a partir da $21^{\mathrm{a}}$ colheita, ocorrida no dia 15-05-05 (Figura 1), devido ao aparecimento dos sintomas do PWV nos frutos. Cabe destacar que não houve necessidade de promover a eliminação de plantas com sintomas do PWV nas folhas, pois o início dos sintomas ocorreu no dia 26-01-05, período em que o pomar se encontrava em pleno florescimento. Esse manejo é preconizado por Rezende (2006).

Considerando o plantio tardio das mudas (04-10-04) e a ocorrência do PWV a partir de 26-01-05, obteve-se uma excelente produtividade (27,12 t/ha) (Tabela 2), quando se compara a média brasileira de 13,44 t/ha (IBGE, 2006), em condições de sequeiro. Pelo que foi apresentado, o uso de irrigação localizada pode ser considerado um importante instrumento para o manejo do PWV em plantio de ciclo anual.

Em função de um plantio antecipado (20-08-05) em comparação ao $1^{\circ}$ ano (04-10-04), obteve-se no $2^{\circ}$ ano um período mais amplo de colheita e, principalmente, percentual superior de frutos $3 \mathrm{~A}(30 \%)$ em relação à colheita do $1^{\circ}$ ano $(16 \%)$. Os frutos tipo indústria apresentaram um crescimento constante e acima de $10 \%$ dos frutos colhidos a partir da $40^{\text {a }}$ colheita (19-04-06), atingindo os $33 \%$ no final da safra e ultrapassando os $22 \%$ da safra de 2005 (Tabela 1 e Figura 2). O aumento progressivo desses tipos de frutos também foi devido ao surgimento dos sintomas da virose.

A antecipação de plantio, somado ao maior período para o início dos sintomas de PWV no pomar (135 dias), quando comparado com o $1^{\circ}$ ano de plantio (113 dias), justificam a produtividade de 29,4 thaa ${ }^{-1}$, superior em 2,3 t.ha ${ }^{-1}$, em relação à safra de 2005. Gioria (1999) verificou que, quanto mais cedo as plantas se infectarem, as perdas são maiores. Mudas que se infectaram aos 2 meses de idade, as perdas tanto em número como em peso chegaram a $80 \%$; já, as mudas que se infectaram aos 4 e 6 meses, as perdas foram de 74 e $44 \%$, respectivamente. Estes resultados reforçam a importância da implantação de estufas teladas no sistema de produção de mudas de maracujá nas diferentes regiões produtoras do Brasil.

Distante aproximadamente dois quilômetros da área comercial estudada, localizou-se, no final do $2^{\circ}$ ciclo anual de produção, a presença de duas plantas de maracujá-amarelo sobre pérgula, que eram utilizadas para sombreamento do veículo do caseiro da propriedade vizinha. As plantas apresentavam sintomas do vírus do endurecimento dos frutos, porém não foi possível eliminá-las. Talvez a implantação de portaria estadual específica sobre a obrigatoriedade de eliminação de plantas com sintomas do PWV, no final da safra em São Paulo, à semelhança de processo implantado para o sistema de produção do mamão no Espírito Santo, possa revitalizar a cadeia do maracujazeiro.

Através das Tabelas 2 e 3, pode-se verificar que a rentabilidade cresceu de $25,35 \%$ para $145,99 \%$ entre o $1^{\circ}$ e o $2^{\circ}$ ano, respectivamente. Observam-se dois pontos extremamente positivos, ou seja, a sustentabilidade da produção no plantio em ciclo anual e uma perspectiva favorável do mercado de fruta in natura e processada de maracujá-amarelo, possivelmente decorrente da presença do vírus do endurecimento dos frutos nas principais regiões produtores de maracujá, associados a outros fatores mencionados por Rossi (2002).

A associação de melhores preços com aumento do percentual de frutos in natura, na safra de 2006, resultou em maior receita bruta obtida em relação à safra de 2005 (Tabelas $2 \mathrm{e}$ 3 ). Além disso, tem-se uma redução substancial dos custos no $2^{\circ}$ ano, decorrente do aproveitamento dos investimentos fixos realizados no $1^{\circ}$ ano. Esses fatores combinados promoveram uma significativa elevação de rentabilidade da atividade de $\mathrm{R} \$ 5.320,47$ $(25,35 \%)$ no $1^{\circ}$ ano, para R $\$ 18.590,51(145,99 \%)$ no $2^{\circ}$ ano (Tabela $3)$.

Pizzol et al. (1999), ao avaliarem uma amostra de produtores da Associação dos Fruticultores da região de Vera Cruz (Afruvec), obtiveram um custo de produção de R \$ 9.507,56 $\mathrm{ha}^{-1} \mathrm{e}$ valor líquido de $\mathrm{R} \$ 1.102,40 \mathrm{ha}^{-1}$, com taxa interna de retorno de 4,5\% ao mês. De acordo com Rossi (2004), os preços médios de maracujá-amarelo, no mercado atacadista, apresentaram variações significativas no período entre 1995 e 2003, oscilando de pouco mais de $\mathrm{R} \$ 1,60 \mathrm{em} \mathrm{1995}$, ano da entrada do Plano Real, para R $\$ 0,66$ por kg em 2002. Ainda segundo o autor, os anos de 1999 e 2000 apresentaram, respectivamente, preços de $\mathrm{R} \$ 0,89$ e $\mathrm{R} \$ 0,91$ por quilo.

TABELA 1 - Produção de frutos de maracujá-amarelo por calibre ( $\mathrm{kg} \mathrm{e} \mathrm{\% ):} \mathrm{3A} \mathrm{(diâmetro} \mathrm{maior} \mathrm{que} 85 \mathrm{~mm}$ ); $2 \mathrm{~A}$ (75$85 \mathrm{~mm}$ ); 1 A (65-75 mm); $2^{\mathrm{a}}$ linha (frutos 1; 2 e $3 \mathrm{~A}$ com defeitos leves) e indústria (menor que $55 \mathrm{~mm}$ ou com defeitos graves) e produção total ( $\mathrm{t} / \mathrm{ha} \mathrm{e}$ $\mathrm{kg} / \mathrm{planta}$ ), durante as safras de 2005 e 2006.

\begin{tabular}{ccccc}
\hline Calibre dos frutos & \multicolumn{2}{c}{$\mathbf{1}^{\mathbf{0}}$ ano $\mathbf{( 2 0 0 5 )}$} & \multicolumn{2}{c}{$\mathbf{2}^{\mathbf{0}}$ ano $\mathbf{( 2 0 0 6 )}$} \\
& $\mathbf{k g}$ & $\mathbf{\%}$ & $\mathbf{~ g g}$ & $\mathbf{\%}$ \\
\hline $\mathbf{3 A}$ & 4,244 & 16 & 8.697 & 30 \\
$\mathbf{2 A}$ & 7.256 & 27 & 5.726 & 19 \\
$\mathbf{1 A}$ & 5.556 & 20 & 1.520 & 05 \\
$\mathbf{2}^{\mathbf{a}}$ linha & 4.080 & 15 & 3.714 & 13 \\
Indústria & 5.972 & 22 & 9.770 & 33 \\
\hline Produção total (t/ha) & \multicolumn{3}{c}{27,12} \\
\hline
\end{tabular}


TABELA 2 - Preço médio por kg de maracujá-amarelo, comercializado pela BauruFrutas, para mesa e indústria, nas safras de 2005 e 2006. Bauru (SP).

\begin{tabular}{cccccc}
\hline & \multicolumn{4}{c}{ Calibre dos frutos } \\
Anos & 3A & 2A & 1A & $2^{\text {a linha }}$ & Indústria \\
\hline $\mathbf{2 0 0 5}$ & $\mathrm{R} \$ 1,28$ & $\mathrm{R} \$ 1,16$ & $\mathrm{R} \$ 1,00$ & $\mathrm{R} \$ 0,77$ & $\mathrm{R} \$ 0,63$ \\
$\mathbf{2 0 0 6}$ & $\mathrm{R} \$ 1,37$ & $\mathrm{R} \$ 1,29$ & $\mathrm{R} \$ 1,14$ & $\mathrm{R} \$ 0,99$ & $\mathrm{R} \$ 0,69$ \\
\hline
\end{tabular}

TABELA 3 - Custo de produção e rentabilidade de 1 ha de maracujá-amarelo irrigado por gotejamento, no espaçamento 2,5 x 2,5 m, em ciclo anual. Bauru-SP, 2006.

\begin{tabular}{|c|c|c|c|}
\hline \multicolumn{2}{|r|}{$\begin{array}{c}\text { RESUMO } \\
(\text { Mão-de-obra + insumos }+ \text { serviços + investimentos) }\end{array}$} & \multirow{2}{*}{$\begin{array}{r}\text { Custo/atividade } \\
\mathrm{R} \$ 364,18\end{array}$} & \multirow{2}{*}{$\begin{array}{c}\begin{array}{c}\text { \% sobre } 0 \\
\text { custo }\end{array} \\
1,74 \%\end{array}$} \\
\hline 1 & $\begin{array}{l}\text { Serviços preliminares: análises de solo, nematóide, quebra-vento e } \\
\text { controle de formigas }\end{array}$ & & \\
\hline 2 & Preparo do solo e calagem em área total & $\mathrm{R} \$ 430,58$ & $2,06 \%$ \\
\hline 3 & $\begin{array}{l}\text { Construção da espaldeira: } 80 \text { palanques; } 187 \text { repiques; } 533 \text { escoras } \\
\text { bambu; } 40 \text { catracas; } 4 \text { rolos de arame; Mão-de-Obra }\end{array}$ & $\mathrm{R} \$ 5.254,45$ & $25,03 \%$ \\
\hline 4 & Abrir, Adubar e misturar fertilizantes nos sulcos & $R \$ 2.131,50$ & $10,16 \%$ \\
\hline 5 & Cerca de proteção contra lebrão & $\mathrm{R} \$ 1.302,97$ & $6,21 \%$ \\
\hline 6 & Irrigação por gotejamento por gravidade & $\mathrm{R} \$ 1.700,99$ & $8,10 \%$ \\
\hline 7 & Plantio de 1.600 mudas & $\mathrm{R} \$ 588,00$ & $2,80 \%$ \\
\hline 8 & Adubações de cobertura & $\mathrm{R} \$ 824,55$ & $3,94 \%$ \\
\hline 9 & Aplicação de defensivos & $\mathrm{R} \$ 1.181,10$ & $5,63 \%$ \\
\hline 10 & $\begin{array}{c}\text { Tratos Culturais: desbrotas, poda de formação, polinização manual, } \\
\text { capinas e monitoramento }\end{array}$ & $\mathrm{R} \$ 2.096,03$ & $9,98 \%$ \\
\hline 11 & Colheita & $\mathrm{R} \$ 805,71$ & $3,84 \%$ \\
\hline 12 & Compra de 80 caixas plásticas & $\mathrm{R} \$ 816,00$ & $3,89 \%$ \\
\hline 13 & Mensalidade Associação & $\mathrm{R} \$ 360,00$ & $1,72 \%$ \\
\hline \multirow[t]{10}{*}{14} & Comissão sobre venda + transporte & $\mathrm{R} \$ 3.132,48$ & $14,92 \%$ \\
\hline & Custo de produção em ciclo anual $\left(\mathrm{C}_{1}\right)$ & R\$20.988,53 & $100 \%$ \\
\hline & Produtividade no $1^{\circ}$ ano & \multirow{2}{*}{\multicolumn{2}{|c|}{$\begin{array}{c}27,12 \text { t/ha } \\
\mathrm{R} \$ 26.309,00\end{array}$}} \\
\hline & Faturamento $1^{0}$ ano & & \\
\hline & Lucro (L) e $\mathbf{L} / \mathbf{C}_{1}$ & $\mathrm{R} \$ 5.320,47$ & $25,35 \%$ \\
\hline & $\begin{array}{l}\text { Investimentos (I): madeira, catracas, arame, cerca para lebrão, quebra } \\
\text { vento, irrigação, caixas plásticas }\end{array}$ & \multicolumn{2}{|c|}{$\mathrm{R} \$ 8.254,24$} \\
\hline & Custo de produção no $2^{0}$ ano $\left(\mathrm{C}_{2}\right)$ & \multicolumn{2}{|c|}{$\left(C_{1}-I\right)=R \$ 12.734,29$} \\
\hline & Produtividade no $2^{\circ}$ ano & \multirow{2}{*}{\multicolumn{2}{|c|}{$\begin{array}{c}29,30 \text { tha } \\
R \$ 31.452,39\end{array}$}} \\
\hline & Faturamento $2^{\circ}$ ano & & \\
\hline & Lucro (L2) e L2/C2 & $\mathrm{R} \$ 18.590,51$ & $145,99 \%$ \\
\hline
\end{tabular}

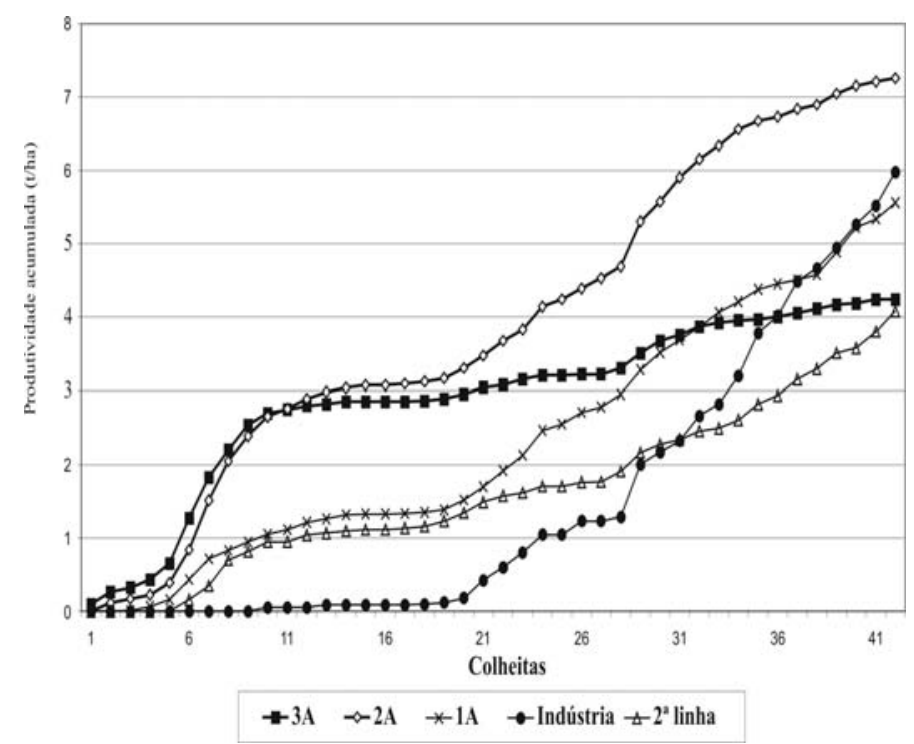

FIGURA 1 - Produção acumulada de maracujá-marelo $\left(\mathrm{t} \mathrm{ha}^{-1}\right)$, durante a safra do $1^{\circ}$ ano (2005). Bauru-SP.

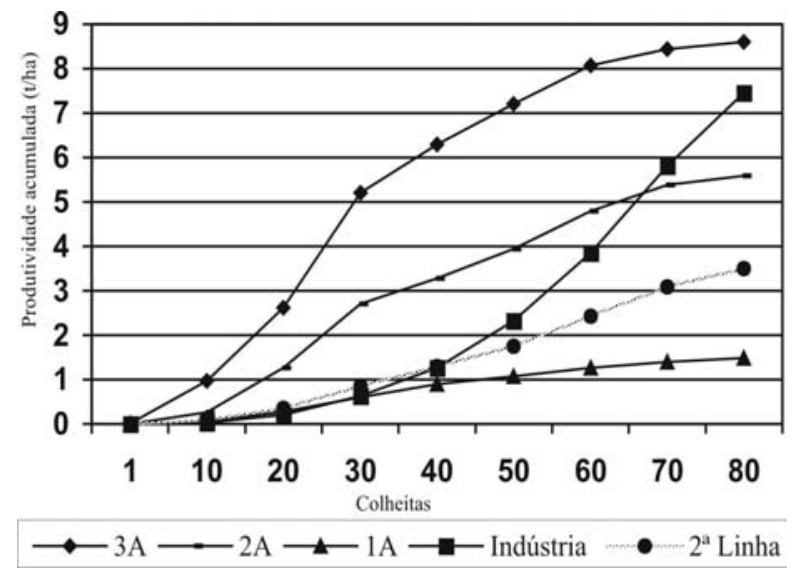

FIGURA 2- Produção acumulada de maracujá-amarelo (t/ha), durante a safra do $2^{\circ}$ ano (2006). Bauru-SP.

\section{CONCLUSÕES}

1- Não houve necessidade de eliminação de plantas com sintomas de virose ("roguing"), pois as mesmas tiveram início após o florescimento do pomar, em ambos os ciclos anuais, o que reforça a importância da produção de mudas em estufa fechada com tela antiafídeo e erradicação de pomares com sintomas de PWV no final da safra.

2- A produtividade do pomar irrigado de maracujá, seleção Afruvec, apresentou média de $28 \mathrm{t} \mathrm{ha}^{-1}$ nos plantios em ciclo anual, bem superior à média nacional de $13,4 \mathrm{t} \mathrm{ha}^{-1}$.

3- $\mathrm{O}$ custo de produção no $1^{\circ}$ e $2^{\circ}$ anos foram, respectivamente, de $\mathrm{R} \$ 20.988,53$ e $\mathrm{R} \$ 12.734,29 / \mathrm{ha}$.

4 - A rentabilidade cresceu de $25,35 \%$ para $145,99 \%$ entre o $1^{\circ}$ e o $2^{\circ}$ ano, ratificando o sucesso das técnicas adotadas no manejo do vírus do endurecimento dos frutos.

\section{REFERÊNCIAS}

BARBOSA, C. J.; SANTOS FILHO, H.P. Endurecimento dos frutos do maracujazeiro. embrapa mandioca e fruticultura tropical, 2005. Disponível em: <http:// www.portaldoagronegocio.com.br>. Acesso em: 11 ago. 2006.

CEAGESP. Classificação do maracujá. São Paulo: Centro de Qualidade em Horticultura, Programa Brasileiro para a Melhoria dos Padrões Comerciais e Embalagens de Hortigranjeiros, 2001.

IBGE. Instituto Brasileiro de Geografia e Estatística. Disponível em: $<$ http://www.ibge.gov.br>. Acesso em: 12 jul 2006.

GIORIA, R. Viroses do maracujazeiro: Incidência na Alta Paulista - SP; danos causados pelo "Passion fruit woodness vírus" (PWV) e sintomatologia do "Cucumber mosaic vírus" (CMV). 1999. 67f. Dissertação (Mestrado) - Escola Superior de Agricultura "Luiz de Queiroz", Universidade de São Paulo, Piracicaba, 1999. 
GIORIA, R., BOSQUÊ, G.G., REZENDE, J.A.M., AMORIM, L., KITAJIMA, E.W. Incidência de viroses de maracujazeiro na Alta Paulista - SP e danos causados pelo "Passion fruit woodiness vírus”. Fitopatologia Brasileira, Brasília, v. 25, p.182-189, 2000.

NASCIMENTO, A.V.S.; SOUZA, A.R.R.; ALFENAS, P.F.; ANDRADE, G.P.; CARVALHO, M.G; PIO-RIBEIRO, G.;ZERBINI, F.M. Análise filogenética de potyvírus causando endurecimento dos frutos do maracujazeiro no Nordeste do Brasil. Fitopatologia Brasileira, Brasília, v.29, n.4, p.378-383, 2004.

NOVAES, Q. S. de. Seleção de estirpes fracas de Passion Fruit Woodness Vírus e tentativas de premunização para o controle do endurecimento dos frutos do maracujazeiro. 2002. $74 \mathrm{f}$. Tese - (Doutorado em Fitopatologia). Escola Superior de Agricultura “Luiz de Queiroz", Universidade de São Paulo, Piracicaba. 2002.

OLIVEIRA, H.J. Incidência e manejo do vírus do endurecimento dos frutos (PWV) no Estado de Minas Gerais. In: Sampaio, A.C., Fumis, T.F., Rossi, A.D., Almeida, A.M., Garcia, M.J.M. (Eds.). Manejo no controle do vírus do endurecimento dos frutos (PWV) do maracujazeiro. Jaboticabal: Multipress, 2006. p. 37-46.

PIZZOL, S.J.S.; MARTINES FILHO, J.G.; CARVALHO, P.H.A.G. Custo de Produção e Viabilidade Econômica da Cultura do Maracujá Amarelo (Passiflora edulis) no Estado de São Paulo. In: CONGRESSO BRASILEIRO DE ECONOMIA E SOCIOLOGIA RURAL, 37., 1999, Foz do Iguaçu (PR). Anais... Foz do Iguaçu: SOBER, 1999 .

REZENDE, J.A.M. Práticas culturais para prevenção e convivência com as viroses do maracujazeiro. In: SAMPAIO, A.C., FUMIS, T.F., ROSSI, A.D., ALMEIDA, A.M., GARCIA, M.J.M. (Eds.).Manejo no controle do vírus do endurecimento dos frutos (PWV) do maracujazeiro. Jaboticabal: Multipress, 2006. p. 47-58.
ROSSI, A.D. Maracujá: um desafio a sustentabilidade da produção. In: REUNIÃO TÉCNICA DE PESQUISA EM MARACUJAZEIRO, 4., 2002, Viçosa. Anais...

ROSSI, A.D. Comercialização de maracujá: situação atual, perspectivas e mercado de exportação, 2004. Disponível em: $<$ http://www.passiflora.org.br>. Acesso em: 15 ago 2006.

SÃO JOSÉ, A.R. A cultura do maracujazeiro nas regiões Norte e Nordeste do Brasil. IN: SIMPÓSIO BRASILEIRO SOBRE A CULTURA DO MARACUJAZEIRO, 5., 1998, Jaboticabal. Anais...Jaboticabal: Afiliada, 1998. p. 3-17.

VIANNA, F.N.P.; FREIRE, F.C.O.; CARDOSO, J.E.; VIDAL, J.C. Principais doenças do maracujazeiro na região Nordeste e seu controle. Fortaleza, 2003. 11p. (Comunicado Técnico 86). Disponível em: $<$ http://www.cnpat.embrapa.br $>$. Acesso em: 11 ago. 2006.

YUKI, V.A.; MIZOTE, F.A.; NARITA, N.; HOJO, H.; HOJO, H.; DELFINO, M.A.; OLIVEIRA, D.A. Epidemiologia do vírus do endurecimento dos frutos do maracujazeiro na região produtora da Alta Paulista, SP. Summa Phytopathologica, Botucatu, v. 32, Supl., p. 19, 2006.

ZERBINI, F.M.; NASCIMENTO, A.V.S.; ALFENAS, P.F.; TORRES, L.B; BRAZ, A.S.K.; SANTANA, E.N.; OTONI, W.C.; CARVALHO, M.G. Resistência ao endurecimento dos frutos em plantas transgênicas de maracujá-amarelo expressando em fragmento do genoma do CABMV., In: SAMPAIO, A.C., FUMIS, T.F., ROSSI, A.D., ALMEIDA, A.M., GARCIA, M.J.M. (Eds.). Manejo no controle do vírus do endurecimento dos frutos (PWV) do maracujazeiro. Jaboticabal: Multipress, 2006. p. 59-68. 